\title{
Epidemiology and return to play following isolated syndesmotic injuries of the ankle: a prospective cohort study of 3677 male professional footballers in the UEFA Elite Club Injury Study
}

\author{
Bart Lubberts, ${ }^{1}$ Pieter D'Hooghe, ${ }^{2}$ Håkan Bengtsson, ${ }^{03}$ Christopher W DiGiovanni, ${ }^{4}$ \\ James Calder, ${ }^{5}$ Jan Ekstrand ${ }^{3}$
}

${ }^{1}$ Orthopaedic Foot and Ankle Service, Massachusetts General Hospital - Harvard Medical School, Boston, Massachusetts, USA

${ }^{2}$ Department of Orthopaedic Surgery, Aspetar Orthopaedic and Sports Medicine Hospital, Doha, Qatar

${ }^{3}$ Department of Medicine and Health, Linköping University, Linköping, Sweden

${ }^{4}$ Department of Orthopaedic Surgery, Massachusetts General Hospital - Harvard Medical School, Boston, Massachusetts, USA

${ }^{5}$ Fortius Clinic, Imperial College, London, UK

\section{Correspondence to}

Dr Bart Lubberts, Orthopaedic Foot and Ankle Service,

Massachusetts General Hospital - Harvard Medical School, Boston, Massachusetts 02114 USA; lubbertsb@gmail.com

Accepted 30 November 2017 Published Online First 21 December 2017

Check for updates

To cite: Lubberts $B$, D'Hooghe $\mathrm{P}$, Bengtsson $\mathrm{H}$, et al. Br J Sports Med 2019:53:959-964.

\section{ABSTRACT}

Aim To determine the epidemiology of isolated syndesmotic injuries in professional football players. Methods Data from 15 consecutive seasons of European professional football between 2001 and 2016 contributed to the dataset of this study. Match play and training data from a total of 3677 players from 61 teams across 17 countries have been included. Team medical staff recorded player exposure and time loss injuries. Injury incidence was defined as the number of injuries per 1000 player-hours. Injury burden was defined as number of days absence per 1000 player-hours. Seasonal trends for isolated syndesmotic injury incidence, isolated syndesmotic injury proportion of ankle ligament injuries and isolated syndesmotic injury burden were analysed via linear regression.

Results The isolated syndesmotic injury incidence was 0.05 injuries per 1000 hours of exposure $(95 \% \mathrm{Cl} 0.04$ to 0.06 ) or one injury per team every three seasons. The injury incidence during match play was 13 times higher compared with during training, $0.21(95 \% \mathrm{Cl} 0.16$ to $0.26)$ and 0.02 (95\% Cl 0.01 to 0.02$)$, respectively. Out of the 1320 ankle ligament injuries registered during the 15 seasons, $94(7 \%)$ were diagnosed as isolated syndesmotic injuries. An annual increase in injury incidence was observed $\left(R^{2}=0.495, b=0.003,95 \% C l\right.$ 0.001 to $0.004, P=0.003)$. However, no significant annual change of injury burden was observed $\left(R^{2}=0.033\right.$ $b=0.032,95 \% \mathrm{Cl}-0.073$ to $0.138, P=0.520$ ). Seventyfour per cent of the injuries were contact related, and the mean $( \pm S D)$ absence following an isolated syndesmotic injury was $39( \pm 28)$ days.

Conclusions The incidence of isolated syndesmotic injuries in elite professional European football annually increased between 2001 and 2016.

\section{INTRODUCTION}

Ankle syndesmosis injury may occur in many forms, commonly classified into isolated ankle syndesmosis injury or with an associated fibula fracture. An isolated injury may occur to any one of the three distinct ligaments (the anterior inferior tibiofibular ligament, the interosseous tibiofibular ligament and the posterior inferior tibiofibular ligament) ${ }^{12}$ but will most commonly involve the anterior inferior tibiofibular ligament. ${ }^{34}$ The most common mechanisms of syndesmotic ligament injury are ankle external rotation and hyperdorsiflexion, causing the talus to rotate in the mortise and the fibula to rotate externally and moving posteriorly and laterally, providing stress to the anterior inferior tibiofibular ligament. ${ }^{3-5}$

Isolated syndesmotic injuries occur more commonly in athletes than in the general population. ${ }^{5-13}$ Certain sports are characterised by a higher proportion of ankle syndesmosis injuries; these include boot immobilised sports ${ }^{5-8}$ such as skiing and ice hockey, as well as collision sports such as American football, wrestling and rugby. 9101214

For football, however, epidemiological data on isolated syndesmotic injuries is limited. Mauntel et $a l^{15}$ studied isolated syndesmotic injuries in 25 sports during six seasons and described the incidence rate, injury mechanism, recurrence and time to return to activity of non-professional football players. Due to differences in competition level, speed of the game, body shape of the players and playing calendar, it is expected that epidemiology and aetiology of syndesmotic injuries differ between non-professional and professional players. A better understanding of how and when professional players incur these injuries may help the development of preventive strategies as well as providing important data regarding expected return to play times. ${ }^{16}$

We aimed to determine the injury incidence and epidemiology of isolated syndesmotic injuries of the ankle in professional football players over a 15 -year period. In addition, we assessed the time to return to competition following an injury.

\section{MATERIAL AND METHODS}

This is a substudy of a long-term prospective cohort study evaluating men's professional football in Europe since $2001 .^{17}$ The current study includes data from 15 consecutive seasons of European professional football between 2001 and 2016. During the study period, a total of 3677 players from 61 teams representing 17 countries have been included (table 1).

\section{Exposure and injury registration}

All first team players in included teams were invited to participate in the study. Participation was voluntary, and written informed consent was obtained at the time of study inclusion. At the beginning of every season, teams appointed a contact person within each respective medical team to be responsible for collecting data and communicating with the study group. During the study period, all individual player exposure during supervised training sessions and matches was recorded on standard attendance records. In addition, all time 
Table 1 Overview of amount of teams, exposure and injuries per season

\begin{tabular}{|c|c|c|c|c|c|c|c|c|c|c|}
\hline Season & Teams & $\begin{array}{l}\text { Exp. total } \\
\text { (hours) }\end{array}$ & $\begin{array}{l}\text { Exp. training } \\
\text { (hours) }\end{array}$ & $\begin{array}{l}\text { Exp. match } \\
\text { (hours) }\end{array}$ & $\begin{array}{l}\text { Ankle } \\
\text { ligament } \\
\text { injuries } \\
\text { (total) (ii) }\end{array}$ & $\begin{array}{l}\text { Ankle ligament } \\
\text { injuries } \\
\text { (training) (ii) }\end{array}$ & $\begin{array}{l}\text { Ankle } \\
\text { ligament } \\
\text { injuries } \\
\text { (match) (ii) }\end{array}$ & $\begin{array}{l}\text { Syn. } \\
\text { injuries } \\
\text { (total)(ii) }\end{array}$ & $\begin{array}{l}\text { Syn. injuries } \\
\text { (training) (ii) }\end{array}$ & $\begin{array}{l}\text { Syn. injuries } \\
\text { (match) (ii) }\end{array}$ \\
\hline $02 / 03$ & 9 & 61777 & 51824 & 9954 & $41(0.66)$ & $12(0.23)$ & 29 (2.91) & $1(0.02)$ & $0(0.00)$ & $1(0.10)$ \\
\hline 03/04 & 11 & 64639 & 53866 & 10773 & $49(0.76)$ & $23(0.43)$ & $26(2.41)$ & $3(0.05)$ & $2(0.04)$ & $1(0.09)$ \\
\hline $04 / 05$ & 9 & 58257 & 48753 & 9504 & $44(0.76)$ & $18(0.37)$ & $26(2.74)$ & $2(0.03)$ & $0(0.00)$ & $2(0.21)$ \\
\hline $06 / 07$ & 17 & 110658 & 93471 & 17187 & $89(0.80)$ & $43(0.46)$ & $46(2.68)$ & $3(0.03)$ & $3(0.03)$ & $0(0.00)$ \\
\hline 07/08 & 14 & 95630 & 80294 & 15336 & $58(0.61)$ & $22(0.27)$ & $36(2.35)$ & $5(0.05)$ & $1(0.01)$ & $4(0.26)$ \\
\hline 08/09 & 14 & 99181 & 83698 & 15483 & $77(0.78)$ & $31(0.37)$ & 46 (2.97) & $3(0.03)$ & $1(0.01)$ & $2(0.13)$ \\
\hline $09 / 10$ & 18 & 123751 & 104534 & 19216 & $73(0.59)$ & $24(0.23)$ & $49(2.55)$ & $7(0.06)$ & $2(0.02)$ & $5(0.26)$ \\
\hline $10 / 11$ & 20 & 132314 & 110755 & 21559 & $83(0.63)$ & $38(0.34)$ & $45(2.09)$ & $5(0.04)$ & $2(0.02)$ & $3(0.14)$ \\
\hline $11 / 12$ & 31 & 213787 & 180742 & 33045 & $145(0.68)$ & $55(0.30)$ & $90(2.72)$ & $10(0.05)$ & $4(0.02)$ & $6(0.18)$ \\
\hline $15 / 16$ & 29 & 208765 & 177506 & 31259 & $91(0.44)$ & $33(0.19)$ & $58(1.86)$ & $8(0.04)$ & $3(0.02)$ & $5(0.16)$ \\
\hline
\end{tabular}

Exp, exposure; ii, injury incidence/1 000 exposure hours; Syn, syndesmotic.

loss injuries that occurred were registered on standard injury cards containing information about type of injury and circumstances of the injury occasion (ie, injury mechanism, affected side, time of injury and reinjury) (table 2). Each month, the appointed contact person reported the attendance records and injury cards to the study group. All injuries were given a diagnostic code by the study group in accordance with the Orchard Sports Injury Classification System (OSICS) 2.0. ${ }^{18}$ OSICS 2.0 codes were used to identify isolated ankle syndesmotic injuries. Athletes with tenderness on palpation over the anterior interosseous membrane proximal to the ankle joint and positive special tests such as ankle external, rotation and syndesmosis squeeze test were suspected for syndesmotic injury. Uncertainty of the diagnosis was resolved through widening of the tibiofibular joint seen during radiographic assessment, or ultrasonographic or MRI evidence of rupture of syndesmotic ligaments without associated fibula fracture. Data collection was undertaken in accordance with a previously published consensus statement regarding how to conduct epidemiological research in professional football. ${ }^{19}$ Methodology related to the exposure and injury registration has previously been described in detail. ${ }^{19}$

\section{Data analysis and statistics}

Data were analysed using SPSS Statistics Version 25. Injury incidence was described as the number of injuries/1000 hours of exposure,

Table 2 Definitions of variables used in the study Team training that involved physical activity under the supervision of the coaching staff

Training session Competitive or friendly match against another team

Match Any physical complaint sustained by a player that resulted from a football match or football training and led to the player being unable to take a full part in future football training or match play

\begin{tabular}{|c|c|}
\hline Moderate injury & Injury causing 8-28 days' absence \\
\hline Severe injury & Injury causing $>28$ days' absence \\
\hline Reinjury & Injury of the same type and at the same site as an index injury \\
\hline Injury incidence & $\begin{array}{l}\text { Number of injuries per } 1000 \text { player-hours }\left(\left(\sum \text { injuries } / \Sigma\right.\right. \\
\text { exposure-hours }) \times 1000)\end{array}$ \\
\hline Injury burden & $\begin{array}{l}\text { Number of days absence per } 1000 \text { player-hours }\left(\left(\sum \text { days }\right.\right. \\
\left.\left.\text { absence } / \sum \text { exposure-hours }\right) \times 1000\right)\end{array}$ \\
\hline
\end{tabular}

with corresponding 95\% CI. Injury incidence in training and match play were calculated, and rate ratio between training and match play were analysed with Poisson regressions using match exposure hours as an offset. The proportion of match injuries occurring in different 15 min periods of match halves were compared with the expected 33\% proportion, which would be present if injuries were evenly distributed between the different thirds, and analysed with Z-statistics. Injury severity was defined by the number of days of absence caused by the injuries and described with mean $( \pm S D)$ and median (25th and 75 th percentiles). Injury burden was defined as number of day's absence/ 1000 hours of exposure. Injury burden in training and match play were calculated, and injury burden ratio between training and match play were analysed with Poisson regressions using match exposure hours as an offset.

The annual changes in injury incidence, injury burden and syndesmotic injury proportion (proportion of all ankle ligament injuries that were diagnosed as syndesmotic injuries) were analysed using linear regression. In these analyses, injury incidence, injury burden and syndesmotic injury proportion were used as dependent variables in separate analyses, while season was used as the independent variable in all analyses. In addition, injury incidence, injury burden and syndesmotic injury proportion in match play were also analysed using linear regression with season included as the independent variable. Analyses of training injuries specifically were not performed since the number of injuries during training were few.

To reduce possible effects of large temporary variations between seasons, moving averages (MA) of two consecutive seasons were also used as dependent variables in similar linear regression analyses. All analyses were two sided, and the significance level was set at $\mathrm{P}<0.05$.

\section{RESULTS}

\section{Isolated syndesmotic injury incidence}

The overall isolated syndesmotic injury incidence over the study period was 0.05 injuries per 1000 hours of exposure (95\% CI 0.04 to 0.06 ) or one injury per team every three seasons. The injury incidence during match play was 13 times higher compared with the incidence during training, 0.21 (95\% CI 0.16 to 0.26 ) and 0.02 (95\% CI 0.01 to 0.02 ), respectively (relative risk 12.63; 
Injury incidence

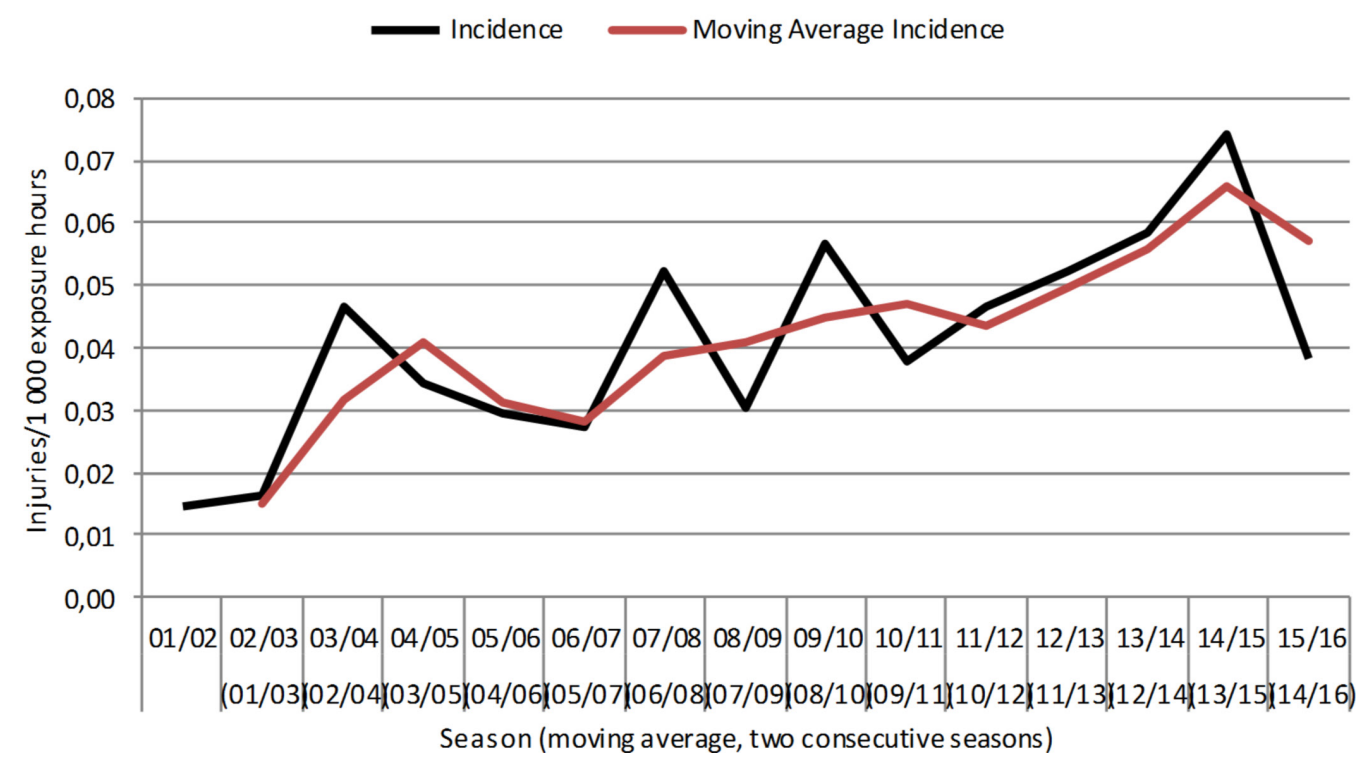

Figure 1 Seasonal variation in injury incidence of syndesmotic injuries in professional football.

95\% CI 8.12 to 19.65$)$. A significant annual increase in isolated syndesmotic injury incidence in general $\left(\mathrm{R}^{2}=0.495, \mathrm{~b}=0.003\right.$, $95 \% \mathrm{CI} 0.001$ to $0.004, \mathrm{P}=0.003)$ as well as in match play $\left(\mathrm{R}^{2}=0.354, \mathrm{~b}=0.013,95 \% \mathrm{CI} 0.002\right.$ to $\left.0.023, \mathrm{P}=0.019\right)$ was observed over the 15 seasons (figure 1 ).

The sensitivity analyses, using MAs of two consecutive seasons, also showed an annual increase in syndesmotic injury incidence in general $\left(\mathrm{R}^{2}=0.822, \mathrm{~b}=0.003,95 \% \mathrm{CI} 0.002\right.$ to $0.004, \mathrm{P}<0.001)$ as well as in match play $\left(\mathrm{R}^{2}=0.751, \mathrm{~b}=0.015\right.$, 95\% CI 0.009 to $0.020, \mathrm{P}<0.001$ ).

Isolated syndesmotic injury proportion of all ankle ligament injuries

Out of the 14653 injuries registered during the 15 seasons, 1950 (13\%) affected the ankle with 1320 (9\%) ankle ligament injuries. Out of these 1320 injuries, 94 (7\%) were diagnosed as syndesmotic injuries. An annual increase of the proportion of syndesmotic injuries (proportion of all ankle ligament injuries that were diagnosed as syndesmotic injuries) was observed $\left(\mathrm{R}^{2}=0.601, \mathrm{~b}=0.006,95 \% \mathrm{CI}\right.$ 0.003 to $0.009, \mathrm{P}=0.001$ ) (figure 2 ). The proportion of syndesmotic injuries during match play also increased annually $\left(R^{2}=0.430\right.$, $\mathrm{b}=0.006,95 \%$ CI 0.002 to $0.010, \mathrm{P}=0.008$ ).

The sensitivity analyses, using MAs of two consecutive seasons, also showed an annual increase in the proportion of syndesmotic injuries in general $\left(\mathrm{R}^{2}=0.818, \mathrm{~b}=0.006,95 \% \mathrm{CI} 0.004\right.$ to 0.008 , $\mathrm{P}<0.001)$ and in match play $\left(\mathrm{R}^{2}=0.758, \mathrm{~b}=0.006,95 \% \mathrm{CI}\right.$ 0.004 to $0.009, \mathrm{P}<0.001)$.

\section{Injury patterns}

Seventy per cent of the syndesmotic injuries occurred during match play and the remaining 30\% during training. Being tackled was responsible for one-third of the syndesmotic injuries. The

\section{Syndesmotic injury proporti on of all a nkle ligament injuries}

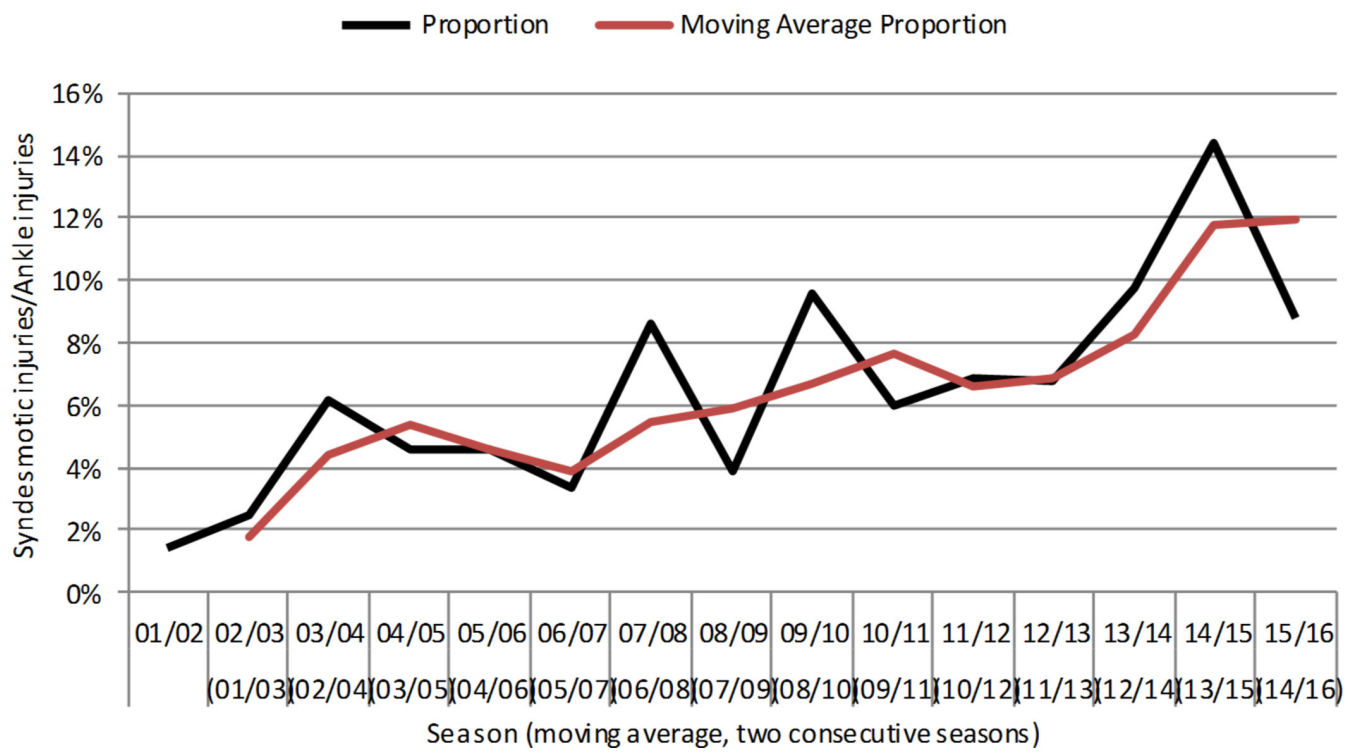

Figure 2 Seasonal variation of the proportion of syndesmotic injuries of all ankle ligament injuries in professional football. 


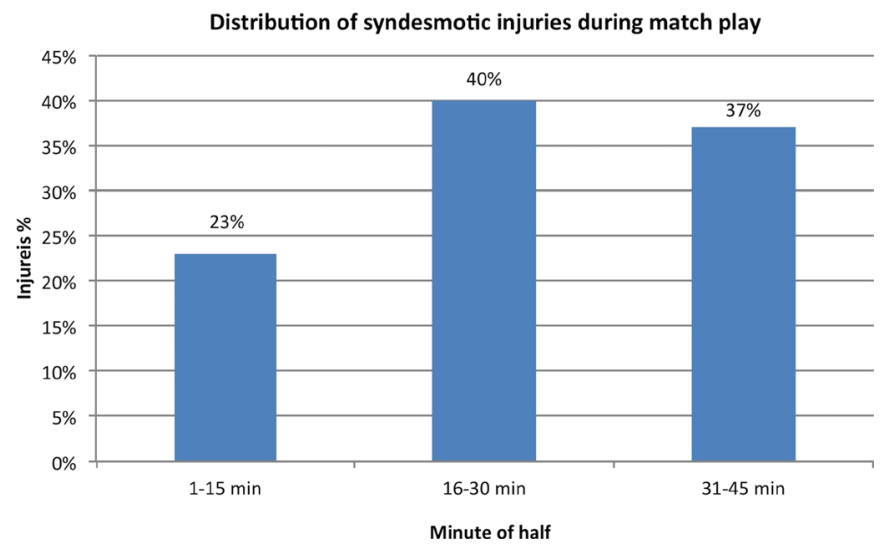

Figure 3 Distribution of syndesmotic injuries during 15 min periods of match play in professional football.

remaining injuries were accounted for by: twisting/turning (13\%), landing from a jump (10\%), collisions (5\%), being kicked (5\%), tackling (4\%) and other (10\%), and for $20 \%$ the mechanism was unknown. Seventy-four per cent of the injuries involved contact of some kind and 54\% affected the dominant leg (defined as the preferred kicking leg). Seven per cent were considered reinjuries. No significant differences were found between the proportion of injuries occurring during 15 min periods of each half $(0-15$, 16-30 and 31-45 $\mathrm{min}$ ) and the 33\% that would be expected if the injuries were evenly distributed between the different thirds of the match halves (figure 3).

\section{Injury severity and absence}

More than $90 \%$ of the syndesmotic injuries were classified as moderate to severe (causing more than 1 week absence) with $57 \%$ being severe (causing more than 1 month absence). The mean (SD) absence following a syndesmotic injury was 39 (28) days and the median (25th and 75th percentiles) was 34 days (19 and 52).

\section{Isolated syndesmotic injury burden}

A total of 3652 days of absence due to syndesmotic injuries were reported over the study period, representing an injury burden of 1.8 days absent per/ 1000 hours of exposure. The injury burden due to match exposure was 18 (RR 18.22 ; 95\% CI 16.86 to 19.68 ) times higher compared with training ( 8.8 days absent/1000 match hours vs 0.5 days absent per 1000 training hours). There were no significant annual changes in injury burden in general $\left(\mathrm{R}^{2}=0.033\right.$, $\mathrm{b}=0.032,95 \% \mathrm{CI}-0.073$ to $0.138, \mathrm{P}=0.520)$ or in match play $\left(\mathrm{R}^{2}=0.003, \mathrm{~b}=0.060,95 \% \mathrm{CI}-0.598\right.$ to $\left.0.718, \mathrm{P}=0.847\right)$.

Similarly, no annual change in general $\left(\mathrm{R}^{2}=0.059, \mathrm{~b}=0.028\right.$, $95 \% \mathrm{CI}-0.043$ to $0.099, \mathrm{P}=0.405)$ or in match play $\left(\mathrm{R}^{2}=0.005\right.$, $\mathrm{b}=0.050,95 \% \mathrm{CI}-0.389$ to $0.488, \mathrm{P}=0.809$ ) was shown when the two-season MA of injury burden was analysed (figure 4).

\section{DISCUSSION}

The incidence figures indicate that an isolated syndesmotic injury in professional football is a relatively rare event. Despite this, the injury incidence during match play seems to have increased over the past 15 seasons. Return to play after injury took on average greater than 5 weeks.

\section{Comparison with other sports}

Isolated syndesmotic injuries are more common in collision sports and those that involve rigid immobilisation of the ankle in a boot. ${ }^{20}$ In a cohort consisting of National Collegiate Athletic Association (NCAA) American football players, the incidence of syndesmotic injury during games was 1.6 per 1000 athlete exposures (defined as one athlete participating in one practice or competition in which there was a possibility for athletic injury). ${ }^{21}$ Flik $e t a l^{8}$ collected injury data from 12 NCAA Division I ice hockey teams over one season and found that the game injury was 0.93 per 1000 athlete exposures. For rugby, the injury rate per 1000 hours of exposure was 0.89 in Rugby Union and 0.46 in Rugby League. ${ }^{22}$ In our study, the syndesmotic injury incidence rate during match play over the study period was 0.21 injuries per 1000 hours of exposure. Accounting $90 \mathrm{~min}$ exposure for each match played, the incidence of syndesmotic injury during games was 0.32 per 1000 athlete exposures. Hence, the risk of incurring a syndesmotic injury playing football is lower compared with American football, ice hockey or rugby.

\section{Professional versus non-professional football players}

Mauntel et $a l^{15}$ described the epidemiology of isolated syndesmotic injuries among college student-athletes in 25 sports over

\section{Injury burden}

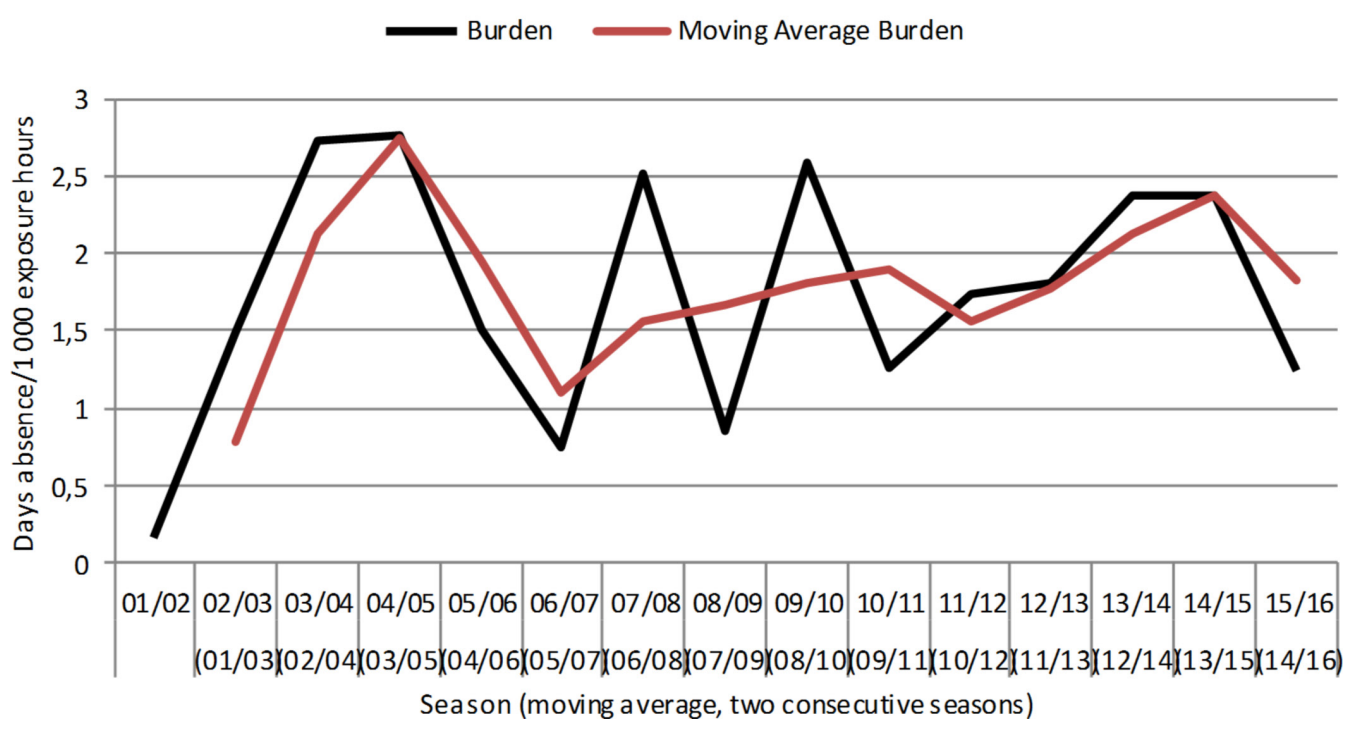

Figure 4 Seasonal variation in injury burden of syndesmotic injuries in professional football. 
six seasons. Similarly with our findings, the injury incidence during match play was 0.34 per 1000 athlete exposures, and the injury incidence during training was 0.047 per 1000 athlete exposures. Compared with professional players, fewer injuries were caused by contact $(74 \%$ among professional players vs $56 \%$ among non-professional players). Interestingly, the absence following an isolated syndesmotic injury was in $80 \%$ of the injuries less than 21 days. Previous studies, including ours, have described an absence ranging from 30 days to 62 days. ${ }^{73-25} \mathrm{~A}$ possible explanation could be that some lateral ankle sprains may have been misdiagnosed and diagnosed as syndesmotic injuries instead. Unfortunately, the authors did not describe the methods used for diagnosing the injury.

\section{Yearly increase in injury incidence}

Over the 15 seasons, an annual increase in isolated syndesmotic injury incidence in general $(0.003$ injuries per 1.000 hours $)$ as well as in match play (0.013 injuries per 1.000 hours) was observed (figure 1). This might be a reflection of the fact that today's healthcare providers have greater suspicion for the injury, or perhaps because of the more frequent use of MRI or diagnostic arthroscopy. ${ }^{2426}$ Another explanation could be a general philosophical change in the way clubs attend to player complaints. ${ }^{27}$ Nonetheless, our data showed that being tackled caused most injuries, and the injury happened 13 times more frequently during match play then during a training session. Hence, we propose that the increase in annual injury incidence is caused by a more aggressive style of play during matches over the 15 years.

\section{Low proportion of syndesmotic injury}

Isolated syndesmotic injuries accounted for $7 \%$ of all ankle ligament injuries. The reported proportion of isolated syndesmotic injuries among overall ankle ligament injuries ranges from $18 \%$ to $74 \% .^{78102128-30}$ This variation can be explained by the fact that some sports have extrinsic risk factors associated with syndesmotic injury. Skiers and ice hockey players wear boots causing rigid immobilisation of the ankle leading to high-torque external rotation of the foot, ${ }^{578}$ and American football is often played on artificial turf instead of natural surfaces. ${ }^{10212830}$ Another plausible explanation is that an isolated syndesmotic injury can be frequently misdiagnosed as an ankle sprain.

\section{Injury burden}

The average absence from play following a syndesmotic injury was 39 days. This is in line with findings from previous studies that reported prolonged time to return to play after a syndesmotic injury, ranging from 30 days to 62 days. ${ }^{723-25}$ In contrast, following lateral ankle sprains, the absence has been reported 15 days. ${ }^{31}$ In addition, over the course of 15 seasons, we found no change in injury burden despite the injury incidence having increased. Hence, the time to return to play after injury over the past 15 seasons has decreased. A reason for this decrease could be that recent research on treatment strategies and diagnosing the severity of the injury may have lead to improved outcomes. ${ }^{1123}{ }^{32-34}$ Nevertheless, to reduce the risk and consequences of this injury to a team, club medical staff should be conscious of whether the injury is stable or unstable since each requires different treatment strategies. ${ }^{11}$ Appropriate management of syndesmotic injuries leads to an earlier return to play. ${ }^{23}$ In addition, use of ankle braces, ${ }^{35}$ referees being stricter while judging player tackling and changes to game play rules, such as sliding, may help reduce the injury incidence rate.

\section{Strengths and study limitations}

The strength of this study is the large homogenous dataset prospectively collected among 61 professional football teams. Having many teams working together provides robust data from which to draw conclusions. ${ }^{16} 36$ There are, however, a few limitations. We were not able to capture data on possible confounders and these could therefore not be included in our analyses. First, the injury form did not capture the examination findings or diagnostic tests results to classify syndesmotic injuries beyond identifying a lack of fracture or provide information on associated injuries. Second, the diagnosis was made by the medical staff of each football team and thus subject to the biases and experience of different physicians. Increasing awareness of the diagnosis of 'syndesmosis injury' may explain part of the trend to increased incidence. Third, we did not capture data on pitch or weather conditions at the time of injury. Fourth, we did not capture data on player medical history (ie, previous syndesmotic or ankle ligament injury). Fifth, there was no information available on how players were treated (ie, conservatively or surgically). These data would have been useful to provide better perspective with respect to interpreting absentee time following the injury.

\section{CONCLUSION}

Our findings indicate a significant increase in the incidence of isolated syndesmotic injuries in professional football players. We speculate this is likely caused by more aggressive playing style during matches. The average return to play time following injury exceeded 5 weeks, and there was no change found in injury burden over 15 seasons. We recommend club medical staff to be conscious of the nature of the injury to reduce the consequences of such injuries to a team. In addition, intensifying preventative work can help reduce the injury incidence rate.

Acknowledgements The authors would like to thank the participating teams (coaching and technical staff, medical teams and players) for their participation in the study.

Contributors All authors were responsible for the conception and design of the study. HB and JE have been involved in the data collection over the study period. HB conducted the analyses, which were planned and checked with BL and PD. All

What are the findings?

- Injury incidence during match play has increased over the past 15 seasons.

- Isolated syndesmotic injury in football is most commonly caused by tackling.

Average return to play after injury exceeds 5 weeks.

\section{How might it impact on clinical practice in the future?}

Our findings may assist in making football players, coaches, referees and the club medical staff aware of isolated syndesmotic injury and its consequences.

- Our findings may contribute to the development of injury prevention strategies in football as they demonstrate that isolated syndesmotic injuries are most commonly caused by player-tackling. 
authors contributed to the interpretation of the findings. BL wrote the first draft of the paper, which was critically revised by PD, HB, CWD, JC and JE. The final manuscript has been approved by all authors.

Funding The Football Research Group was established in Linköping, Sweden, in collaboration with Linköping University and through grants from the UEFA, the Swedish Football Association, the Football Association Premier League Limited and the Swedish National Centre for Research in Sports.

Competing interests None declared.

Patient consent Obtained.

Ethics approval The study design was approved by the UEFA Medical Committee and the UEFA Football Development Division.

Provenance and peer review Not commissioned; externally peer reviewed.

Data sharing statement Due to confidentiality reasons, there are no data that can be shared.

(c) Article author(s) (or their employer(s) unless otherwise stated in the text of the article) 2019. All rights reserved. No commercial use is permitted unless otherwise expressly granted.

\section{REFERENCES}

1 Hermans JJ, Beumer A, de Jong TA, et al. Anatomy of the distal tibiofibular syndesmosis in adults: a pictorial essay with a multimodality approach. J Anat 2010;217:633-45.

2 Williams BT, Ahrberg AB, Goldsmith MT, et al. Ankle syndesmosis: a qualitative and quantitative anatomic analysis. Am J Sports Med 2015;43:88-97.

3 Beumer A, Valstar ER, Garling EH, et al. Effects of ligament sectioning on the kinematics of the distal tibiofibular syndesmosis: a radiostereometric study of 10 cadaveric specimens based on presumed trauma mechanisms with suggestions for treatment. Acta Orthop 2006;77:531-40.

4 Xenos JS, Hopkinson WJ, Mulligan ME, et al. The tibiofibular syndesmosis. Evaluation of the ligamentous structures, methods of fixation, and radiographic assessment. J Bone Joint Surg Am 1995;77:847-56.

5 Fritschy D. An unusual ankle injury in top skiers. Am J Sports Med 1989;17:282-6. discussion 85-6.

6 Clanton TO, Paul P. Syndesmosis injuries in athletes. Foot Ankle Clin 2002;7:529-49.

7 Wright RW, Barile RJ, Surprenant DA, et al. Ankle syndesmosis sprains in national hockey league players. Am J Sports Med 2004;32:1-5.

8 Flik K, Lyman S, Marx RG. American collegiate men's ice hockey: an analysis of injuries. Am J Sports Med 2005:33:183-7.

9 Hopkinson WJ, St Pierre P, Ryan JB, et al. Syndesmosis sprains of the ankle. Foot Ankle 1990;10:325-30.

10 Kaplan LD, Jost PW, Honkamp N, et al. Incidence and variance of foot and ankle injuries in elite college football players. Am J Orthop 2011:40:40-4.

11 Lubberts $B$, van Dijk PAD, Donovan N, et al. Time to return to sports after management of stable and unstable grade II syndesmotic injuries: a systematic review. JISAKOS 2015. doi: 10.1136/ jisakos-2015-000026. [Epub ahead of print 15 Jun 2016].

12 Nussbaum ED, Hosea TM, Sieler SD, et al. Prospective evaluation of syndesmotic ankle sprains without diastasis. Am J Sports Med 2001;29:31-5.

13 Vopat ML, Vopat BG, Lubberts B, et al. Current trends in the diagnosis and management of syndesmotic injury. Curr Rev Musculoskelet Med 2017;10:94-103.

14 Gerber JP, Williams GN, Scoville CR, et al. Persistent disability associated with ankle sprains: a prospective examination of an athletic population. Foot Ankle Int 1998;19:653-60.
15 Mauntel TC, Wikstrom EA, Roos KG, et al. The epidemiology of high ankle sprains in national collegiate athletic association sports. Am J Sports Med 2017;45:2156-63.

16 Ekstrand J. Preventing injuries in professional football: thinking bigger and working together. Br J Sports Med 2016;50:709-10.

17 Waldén M, Hägglund M, Ekstrand J. UEFA Champions League study: a prospective study of injuries in professional football during the 2001-2002 season. Br J Sports Med 2005;39:542-6.

18 Orchard J. Orchard Sports Injury Classification System (OSICS). Sports health 1993;11:39-41.

19 Hägglund M, Waldén M, Bahr R, et al. Methods for epidemiological study of injuries to professional football players: developing the UEFA model. Br J Sports Med 2005;39:340-6.

20 Williams GN, Jones MH, Amendola A. Syndesmotic ankle sprains in athletes. Am J Sports Med 2007;35:1197-207.

21 Hunt KJ, George E, Harris AH, et al. Epidemiology of syndesmosis injuries in intercollegiate football: incidence and risk factors from National Collegiate Athletic Association injury surveillance system data from 2004-2005 to 2008-2009. Clin J Sport Med 2013;23:278-82.

22 Sman AD, Hiller CE, Rae K, et al. Predictive factors for ankle syndesmosis injury in football players: a prospective study. J Sci Med Sport 2014;17:586-90.

23 Calder JD, Bamford R, Petrie A, et al. Stable versus unstable grade II high ankle sprains: a prospective study predicting the need for surgical stabilization and time to return to sports. Arthroscopy 2016;32:634-42.

24 Howard DR, Rubin DA, Hillen TJ, et al. Magnetic resonance imaging as a predictor of return to play following syndesmosis (high) ankle sprains in professional football players. Sports Health 2012;4:535-43.

25 Sman AD, Hiller CE, Rae K, et al. Prognosis of ankle syndesmosis injury. Med Sci Sports Exerc 2014;46:671-7.

26 Takao M, Ochi M, Oae K, et al. Diagnosis of a tear of the tibiofibular syndesmosis. The role of arthroscopy of the ankle. J Bone Joint Surg Br 2003;85:324-9.

27 McCall A, Dupont G, Ekstrand J. Injury prevention strategies, coach compliance and player adherence of 33 of the UEFA Elite Club Injury Study teams: a survey of teams' head medical officers. Br J Sports Med 2016;50:725-30.

28 Boytim MJ, Fischer DA, Neumann L. Syndesmotic ankle sprains. Am J Sports Med 1991;19:294-8.

29 Roemer FW, Jomaah N, Niu J, et al. Ligamentous injuries and the risk of associated tissue damage in acute ankle sprains in athletes: a cross-sectional MRI study. Am J Sports Med 2014;42:1549-57.

30 Osbahr DC, Drakos MC, O'Loughlin PF, et al. Syndesmosis and lateral ankle sprains in the National Football League. Orthopedics 2013;36:e1378-84.

31 Waldén $M$, Hägglund $M$, Ekstrand J. Time-trends and circumstances surrounding ankle injuries in men's professional football: an 11-year follow-up of the UEFA Champions League injury study. Br J Sports Med 2013;47:748-53.

32 Westermann RW, Rungprai C, Goetz JE, et al. The effect of suture-button fixation on simulated syndesmotic malreduction: a cadaveric study. J Bone Joint Surg Am 2014;96:1732-8

33 Förschner PF, Beitzel K, Imhoff AB, et al. Five-year outcomes after treatment for acute instability of the tibiofibular syndesmosis using a suture-button fixation system. Orthop J Sports Med 2017;5:232596711770285.

34 Ryan PM, Rodriguez RM. Outcomes and return to activity after operative repair of chronic latent syndesmotic instability. Foot Ankle Int 2016;37:192-7.

35 McGuine TA, Hetzel S, Wilson J, et al. The effect of lace-up ankle braces on injury rates in high school football players. Am J Sports Med 2012;40:49-57.

36 Ekstrand J, Hägglund M, Waldén M. Injury incidence and injury patterns in professional football: the UEFA injury study. Br J Sports Med 2011;45:553-8. 